\title{
High-dose immunosuppressive therapy and autologous HCT for relapsing-remitting $\mathrm{MS}$

\author{
OPEN $\mathbb{a}$ 全
}

Richard A. Nash, MD

George J. Hutton, MD

Michael K. Racke, MD

Uday Popat, MD

Steven M. Devine, MD

Kaitlyn C. Steinmiller, MS

Linda M. Griffith, MD, MHS, PhD

Paolo A. Muraro, MD, $\mathrm{PhD}$

Harry Openshaw, MD

Peter H. Sayre, MD

Olaf Stuve, MD, PhD

Douglas L. Arnold, MD

Mark H. Wener, MD

George E. Georges, MD

Annette Wundes, MD

George H. Kraft, MD

James D. Bowen, MD

Correspondence to

Dr. Nash:

richard.nash@healthonecares.com

Supplemental data at Neurology.org

\section{ABSTRACT}

Objective: To evaluate the safety, efficacy, and durability of multiple sclerosis (MS) disease stabilization after high-dose immunosuppressive therapy (HDIT) and autologous hematopoietic cell transplantation (HCT).

Methods: High-Dose Immunosuppression and Autologous Transplantation for Multiple Sclerosis (HALT-MS) is a phase II clinical trial of HDIT/HCT for patients with relapsing-remitting (RR) MS who experienced relapses with disability progression (Expanded Disability Status Scale [EDSS] 3.0-5.5) while on MS disease-modifying therapy. The primary endpoint was event-free survival (EFS), defined as survival without death or disease activity from any one of: disability progression, relapse, or new lesions on MRI. Participants were evaluated through 5 years posttransplant. Toxicities were reported using the National Cancer Institute Common Terminology Criteria for Adverse Events (AE).

Results: Twenty-five participants were evaluated for transplant and 24 participants underwent HDIT/HCT. Median follow-up was 62 months (range 12-72). EFS was 69.2\% (90\% confidence interval [Cl] 50.2-82.1). Progression-free survival, clinical relapse-free survival, and MRI activityfree survival were $91.3 \%$ (90\% Cl 74.7\%-97.2\%), 86.9\% (90\% Cl 69.5\%-94.7\%), and $86.3 \%$ (90\% Cl 68.1\%-94.5\%), respectively. AE due to HDIT/HCT were consistent with expected toxicities and there were no significant late neurologic adverse effects noted. Improvements were noted in neurologic disability with a median change in EDSS of -0.5 (interquartile range -1.5 to $0.0 ; p=0.001$ ) among participants who survived and completed the study.

Conclusion: HDIT/HCT without maintenance therapy was effective for inducing long-term sustained remissions of active RRMS at 5 years.

ClinicalTrials.gov identifier: NCT00288626.

Classification of evidence: This study provides Class IV evidence that participants with RRMS experienced sustained remissions with toxicities as expected from HDIT/HCT. Neurology ${ }^{\circledR}$ 2017;88:842-852

\section{GLOSSARY}

AE = adverse event; ASTIMS = Autologous Stem Cell Transplantation International MS Trial; $\mathbf{C l}=$ confidence interval; $\mathbf{C T C A E}=$ Common Terminology Criteria for Adverse Events; DMT = disease-modifying therapy; EDSS = Expanded Disability Status Scale; EFS = event-free survival; FDA = Food and Drug Administration; HALT-MS = High-Dose Immunosuppression and Autologous Transplantation for Multiple Sclerosis; HCT = hematopoietic cell transplantation; HDIT = high-dose immunosuppressive therapy; lgG = immunoglobulin G; IQR = interquartile range; $\mathbf{M S}=$ multiple sclerosis; MSFC = Multiple Sclerosis Functional Composite; MSIS = Multiple Sclerosis Impact Scale; MSRP = Multiple Sclerosis Review Panel; NEDA = no evidence of disease activity; OCB = oligoclonal bands; QoL = quality of life; RRMS = relapsing-remitting multiple sclerosis; SPMS = secondary progressive multiple sclerosis.

Multiple sclerosis (MS) is an autoimmune disease resulting in demyelination and loss of CNS neurons. The High-Dose Immunosuppression and Autologous Transplantation for Multiple Sclerosis (HALT-MS) clinical trial was initiated in participants with relapsing-remitting MS (RRMS); that is, with active CNS inflammation relatively early in the disease course. ${ }^{1}$ We

From the Colorado Blood Cancer Institute (R.A.N.), Denver; Baylor College of Medicine (G.J.H.), Houston, TX; Ohio State University (M.K.R., S.M.D.), Columbus; MD Anderson Cancer Research Center (U.P.), Houston, TX; Rho, Inc. (K.C.S.), Chapel Hill, NC; National Institute of Allergy and Infectious Diseases (L.M.G.), National Institutes of Health, Bethesda, MD; Division of Brain Sciences (P.A.M.), Imperial College London, UK; City of Hope National Medical Center (H.O.), Duarte, CA; Immune Tolerance Network (P.H.S.), University of California San Francisco; University of Texas Southwestern (O.S.), Dallas; NeuroRx (D.L.A.), McGill University, Montreal, Canada; Fred Hutchinson Cancer Research Center (G.E.G.), University of Washington (M.H.W., A.W., G.H.K.); and Swedish Hospital Medical Center (J.D.B.), Seattle, WA. Go to Neurology.org for full disclosures. Funding information and disclosures deemed relevant by the authors, if any, are provided at the end of the article. The Article Processing Charge was funded by The Immune Tolerance Network, which is funded by NIH/NIAID.

This is an open access article distributed under the terms of the Creative Commons Attribution-NonCommercial-NoDerivatives License 4.0 (CC BY-NC-ND), which permits downloading and sharing the work provided it is properly cited. The work cannot be changed in any way or used commercially without permission from the journal. 
hypothesized that high-dose immunosuppressive therapy (HDIT) and autologous hematopoietic cell transplantation (HCT) would remove disease-causing cells and induce a reset of the immune system, thereby controlling disease. ${ }^{2,3}$ Participants had substantial disability progression (Expanded Disability Status Scale [EDSS] 3.0-5.5) and failure of MS disease-modifying therapy (DMT) to control disease activity. At 3 years after HDIT/HCT and, importantly, with no posttransplant immunosuppressive therapy administered, event-free survival (EFS) was $78 \%,{ }^{1}$ defined as absence of progression, relapse activity, or new MRI lesions. Further, peritransplant adverse events (AE) were consistent with those routinely observed after $\mathrm{HDIT} / \mathrm{HCT},{ }^{1}$ and treatment-related mortality was zero. ${ }^{1}$ In this report, outcomes of participants followed at least 5 years are described.

Outcomes at 5 years for participants in the HALT-MS clinical trial compare favorably to results from nontransplant studies that enrolled participants with less severe MS and followed them for only 2-3 years. ${ }^{4}$ HALT-MS is among the first MS treatment clinical trials to use a composite endpoint for EFS that is comparable, but not identical, to no evidence of MS disease activity (NEDA) (including MRI activity, relapse, or progression of disability $)^{4,5}$ as the primary endpoint. Advantages of the composite endpoint include that (1) it is a sensitive indicator of MS disease activity as compared to either relapse activity or progression of disability alone and (2) it facilitates comparison of HDIT/HCT to other MS DMT. ${ }^{4}$ For current Food and Drug Administration (FDA)approved therapies for MS, including glatiramer acetate or interferon- $\beta$ - 1 a (first-line treatments ${ }^{6}$ ), or natalizumab or alemtuzumab (second-line treatments ${ }^{6}$ ), NEDA levels of $19 \%, 21 \%, 37 \%$, and $39 \%$, respectively, were observed with follow-up of 2-3 years after initiation of study treatment. ${ }^{5-8}$ In an observational clinical cohort in which participants received no or multiple different therapies, NEDA was maintained at 1 year in $46 \%$, but at 7 years in only $7 \%$ of participants with MS. ${ }^{9}$

METHODS Details of the patient population, procedures, evaluations, and study design have been reported.
Patients. Eligible patients were 18-60 years of age and had MS by McDonald criteria ${ }^{10}$ with (1) RRMS; (2) EDSS ${ }^{11} 3.0-5.5$ at baseline; (3) lesions on brain MRI consistent with MS; (4) disease duration $<15$ years; and (5) failure of DMT, defined as $\geq 2$ clinical relapses over 18 months while on therapy and associated with EDSS increase (by 1.0 for EDSS of 3.0-3.5 or by 0.5 for EDSS of 4.0-5.5 and sustained $\geq 4$ weeks). Eligibility was determined by a MS Review Panel (MSRP). ${ }^{1}$

Standard protocol approvals, registrations, and patient consent. The clinical study (protocol ITN033AI; BB-IND 12164; type II DMF BB-IND 118211) was approved by institutional review boards at participating sites and participants provided written informed consent. The clinicaltrials.gov registration number is NCT00288626.

Study design. This is a prospective, open-label, single-arm, multicenter phase II clinical trial.

Procedures. Autologous peripheral blood stem cells were collected, CD34-selected, and stored as described. ${ }^{1}$ High-dose chemotherapy was carmustine (BCNU) $300 \mathrm{mg} / \mathrm{m}^{2}$ on day -6 , etoposide $200 \mathrm{mg} / \mathrm{m}^{2}$ and cytarabine $200 \mathrm{mg} / \mathrm{m}^{2}$ daily from day -5 to -2 , and melphalan $140 \mathrm{mg} / \mathrm{m}^{2}$ on day -1 (BEAM). ${ }^{1,12}$ Rabbit antithymocyte globulin $(2.5 \mathrm{mg} / \mathrm{kg} / \mathrm{d})$ was administered on days -2 and -1 . On day $0, \mathrm{CD} 34+$ hematopoietic progenitor cells were thawed and infused. Filgrastim $(5 \mu \mathrm{g} / \mathrm{kg} / \mathrm{d})$ was administered from day +5 until recovery of blood counts. Prednisone was administered $(0.5 \mathrm{mg} / \mathrm{kg} / \mathrm{d})$ from day +7 to +21 and then tapered over 2 weeks to prevent engraftment syndrome. Supportive care was administered as described. ${ }^{13}$

Primary endpoint and study evaluations. The primary endpoint was time until treatment failure or EFS during 5 years post-HCT, defined as the first event of death or disease activity from any one of: (1) disability progression, (2) relapse, or (3) new lesions on MRI. Disability progression was defined as a change in EDSS performed at least 6 months after transplant of $>0.5$ as compared to EDSS at baseline and confirmed 3 months later. ${ }^{1}$ Relapse was defined as new neurologic symptoms lasting over 48 hours. The MRI endpoint was 2 or more gadolinium-enhancing or new T2-weighted lesions at 1 year or longer after transplant. The Multiple Sclerosis Functional Composite (MSFC) and the Multiple Sclerosis Impact Scale (MSIS-29) were performed before mobilization of stem cells, at +6 months, and then annually to end of study. Participants were contacted by telephone between annual visits at an interval of 3 months and if there were new neurologic symptoms, they were evaluated.

Brain MRI was performed at screening post-MSRP, baseline, +2 months, +6 months, and then annually to +5 years, on scanners with $1.5 \mathrm{~T}$ field strength. Scans were analyzed centrally (NeuroRx, Montreal, Canada). The brain MRI at +2 months was the posttreatment reference scan for assessment of treatment failure. The pretreatment screening scan was the reference for brain volume changes.

Toxicities were reported by the National Cancer Institute Common Terminology Criteria for Adverse Events (CTCAE) version 3.0. $\mathrm{AE} \geq$ grade 2 were recorded from 3 to 5 years of the study.

Oligoclonal bands (OCB) were identified/quantified by 2 independent experienced readers following isoelectric focusing on agarose and in-gel enzyme-enhanced immunostaining using an FDA-approved method (Sebia [Norcross, GA] Isofocusing Gel), following consensus guidelines. ${ }^{14}$ Total immunoglobulin $\mathrm{G}(\mathrm{IgG})$ concentrations were measured in CSF and serum specimens to allow normalization of the concentration of IgG applied to each gel lane. Participant paired CSF and serum samples from 
baseline, 2 years, and 4 years posttransplant were assayed on the same gel for accurate comparison of bands. Bands visualized in CSF but not in paired serum specimens were denoted as CSFspecific. Disappearance/resolution of CSF-specific bands and appearance of novel CSF-specific bands in the +2 years and +4 years specimens as compared to the baseline sample of each participant were recorded. Analyses were performed in a CLIAcertified laboratory (Department of Laboratory Medicine, University of Washington, Seattle).

Statistics. EFS was calculated using the Kaplan-Meier method to assess the composite primary endpoint. Similar analyses were conducted for the individual components of disability progression, clinical relapse, new MRI lesions, and death to produce progressionfree, relapse-free, MRI activity-free, and overall survival estimates. Follow-up for any component was not censored by earlier events so that each has an interpretation independent of the other components. Standard errors were derived using the Greenwood formula and used to generate $90 \%$ confidence intervals (CIs).

Secondary outcomes included change in T1 and T2 lesion volumes, total brain volume, EDSS, MSFC, and MSIS. Each component of the MSFC was transformed into a $Z$ score using the National MS Society Task Force Database reference population. ${ }^{15}$ Significant change from baseline was tested using the Wilcoxon signed-rank test. The screening measurement was used as the reference for percent change in brain volume, while the baseline visit was used for all other endpoints. A limitation of this study is that for secondary outcomes no corrections have been made for multiple comparisons, as this pilot study was hypothesisgenerating and not a formal test of specific hypotheses.

All analyses were performed using SAS version 9.3 (Cary, NC) or higher. Datasets for the analyses are available through TrialShare, a public website managed by the Immune Tolerance Network (https://www.itntrialshare.org/HALTMS_5yr.url).

Primary research question. To assess the 5-year durability of disease stabilization in patients with MS after HDIT and autologous HCT.

Classification of evidence. This study provides Class IV evidence that participants with RRMS experienced sustained remissions with toxicities as expected from HDIT/HCT.

RESULTS Patient characteristics. Twenty-five patients were consented and 24 patients underwent HDIT/HCT (figure 1, and figure e-1 and table e-1 at Neurology.org). The 25 entering participants had median age 37 years (interquartile range [IQR] 3142), with 17 (68\%) women. Disease duration was 4.9 years (median; IQR 2.5-7.3); baseline EDSS was 4.5 (median; IQR, 4.0-5.0). Participants had previously failed 3 (median; IQR 2-4) nontransplant MS medications.

Adverse events. AEs to 3 years after transplant were described, ${ }^{1}$ and were consistent with toxic effects associated with HDIT/HCT, including predominantly cytopenias and infections; no acute treatment-related neurologic AE were observed. ${ }^{1}$ Beyond 3 years post-HCT, 15 grade 3 AEs occurred (table 1); no grade 4 AEs were observed.

Two participants had disease progression and died (grade $5 \mathrm{AE}$ ) at $>2.5$ years and $>3.5$ years after transplant and were reported. ${ }^{1} \mathrm{~A}$ third participant also had disease progression at 15 months and died at 4.5 years post-HCT. No information was available on the events leading up to death. The final cause of death was cardiopulmonary arrest. No death was attributed to transplant.

Evaluation of disease. The estimated EFS probability was $73.8 \%(90 \%$ CI $55.0 \%-85.7 \%)$ at 4 years and $69.2 \%(90 \%$ CI $50.2 \%-82.1 \%)$ at 5 years. Of 24 participants transplanted, 7 did not maintain EFS by close of follow-up (figure 2, A-B and table e-2) by an increase in EDSS $>0.5(n=2)$, clinical relapse $(n=3)$, or development of new MRI lesions $(n=2)$. The 5-year progression-free survival was $91.3 \%$ (90\% CI $74.7 \%-97.2 \%$ ), relapse-free survival was $86.9 \%$ (90\% CI 69.5\%-94.7\%), MRI activity-free survival was $86.3 \%$ (90\% CI $68.1 \%-94.5 \%$ ), and overall survival was $86.3 \% \quad(90 \% \quad$ CI $\quad 68.3 \%-94.5 \%)$ (figure 2, C-F, and table e-2).

Three of 24 participants transplanted did not maintain EFS due to clinical relapse, at 5.1, 22.2, and 32.6 months. However, for all participants, including those failing to maintain EFS, relapse activity was reduced posttransplant as compared to pretreatment (figure 1).

The EDSS score, for participants who survived and completed the study, improved after transplant with a median change from baseline of -0.50 (IQR -1.5 to 0.0$)$ at 5 years $(p=0.001$; figure $3 \mathrm{~A}$ and table e-3). Specifically, as compared to baseline pretransplant, 15 participants had improvement $(\geq 0.5$ decrease) in EDSS, 5 remained stable (no change), and 4 progressed ( $\geq 0.5$ increase) at the time of their last EDSS assessment, with 2 failing to maintain EFS due to progression at 15.2 and 18.9 months. The MSFC improved from baseline (figure 3, B-E, and table e-3) by 1 year and this persisted through 3 years after transplant, but by year 5 significant improvement was not sustained ( $p=0.303$ ). MSIS-29 quality of life (QoL) was improved at 3 years; however, only a trend towards improvement was noted at the end of the study (median -8.50 ; IQR -23 to 3.5; $p=0.091$ ) (figure $3 \mathrm{~F}$ and table e-3).

MRI assessments. Two participants failed to maintain EFS at 45.6 and 48.4 months posttransplant due to development of new brain gadolinium-enhancing lesions or T2 lesions (figure 4, A and B). For all participants, T2 lesion volume decreased during follow-up starting at 6 months; at 5 years, there was still a decrease $(p<0.001)$ (figure $4 \mathrm{C})$. T1 lesion volume demonstrated a median increase from baseline and at year 5 remained different from zero $(p=0.015)$ (figure 4D). Brain volume was decreased at 6 months as compared to baseline, but subsequently appeared to stabilize (figure $4 \mathrm{E}$ ). Thus, while brain 


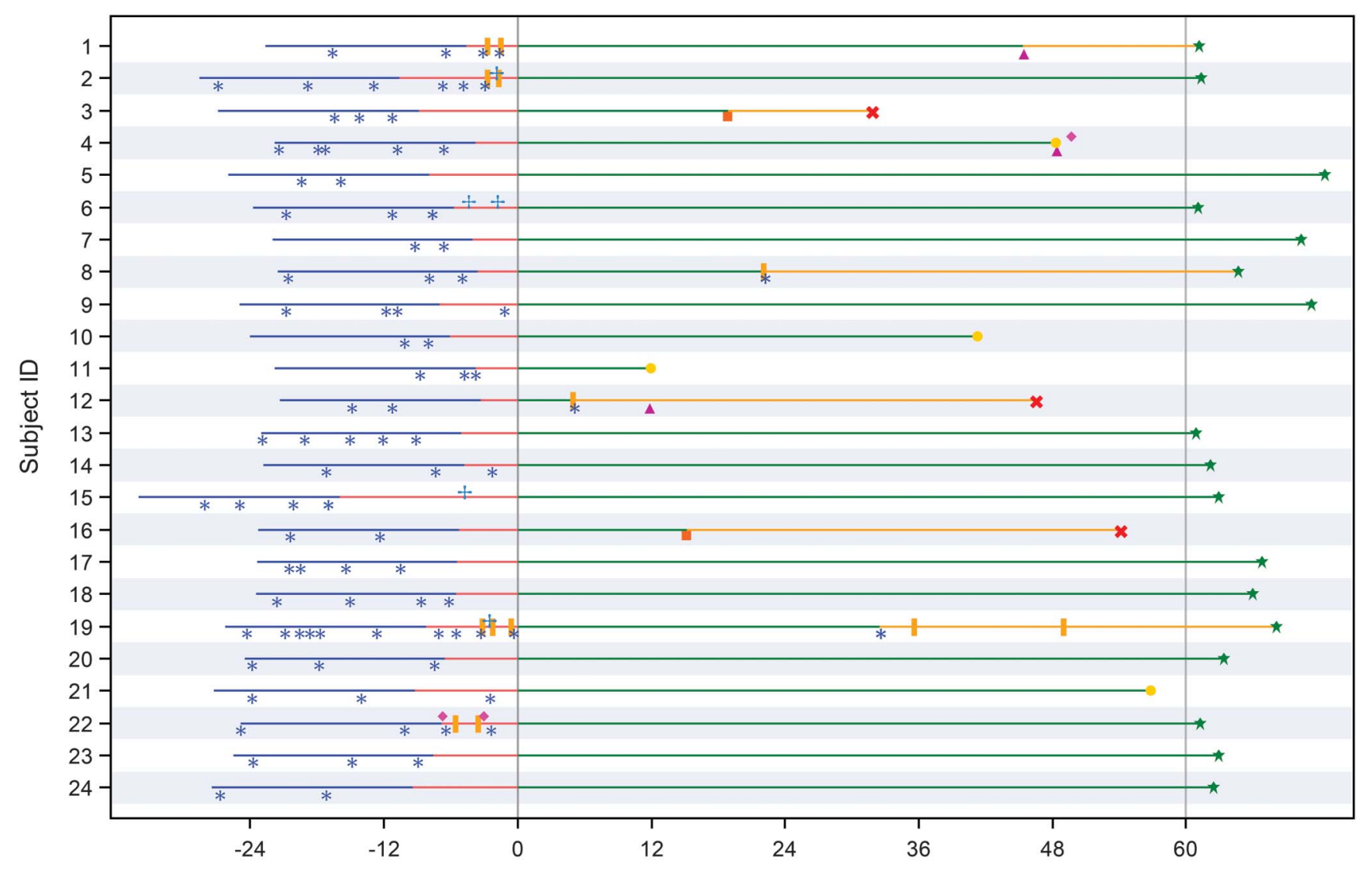

Time since transplant (months)

\begin{tabular}{llll}
\hline Eligibility window & - Screening to transplant & - Follow-up & - Follow-up postprimary endpoint \\
+ MS worsening & I Steroid & DMT & MRI \\
$*$ Relapse & - EDSS & $*$ Death & Early termination \\
$\star$ Study completion & &
\end{tabular}

Patient-level pretransplant characteristics and study outcomes are presented for the 24 transplanted participants. Time is measured in months relative to day 0 , the day of graft infusion. The eligibility window is defined as the period of time beginning 18 months prior to the screening visit. At screening, the number of relapses, as defined in the protocol, that occurred during the eligibility window were identified retrospectively and documented in the clinical database, for the purpose of determining eligibility. The period of screening to transplant is defined as the time from determination of protocol eligibility until day 0 . To obtain a more complete understanding of the events that occurred during the time from screening to day 0 , we retrospectively investigated reports of multiple sclerosis (MS) attack, to determine if the participant had met the protocol definition of relapse, or if the event was a less severe MS worsening event. MS worsening is a new neurologic sign or symptom that does not meet criteria for relapse, and was documented only during the period from screening to day 0 . Patients 2,6 , $14,15,19$, and 22 experienced an Expanded Disability Status Scale (EDSS) increase of at least 0.5 during the period of screening to transplant. Study completion for some participants occurred beyond the 28-day visit window for the year 5 visit, due to scheduling difficulties. The participant flow diagram is presented as figure e-1 in the current publication. A total of 18 participants completed the year 4 assessment and 17 participants completed the year 5 assessment. MS disease activity is reduced for participants posttransplant as compared to prior to treatment. DMT = disease-modifying therapy.

volume at the end of the study was decreased compared to baseline, there was no change in brain volume from year 3 to the end of the study.

OCB evaluation. To investigate the effect of transplant on presence of OCB in the CSF, participant samples were analyzed at baseline and at 2 and 4 years postHCT. There was persistence but a reduction in OCB number in the CSF at 2 years (figure e-2), with a reduction of CSF IgG levels after transplant.

DISCUSSION In this 5-year analysis of HDIT/HCT without posttransplant maintenance therapy for participants with highly active RRMS in the HALTMS study, $69.2 \%$ of participants remained event-free without evidence of relapse, disability progression, or new MRI lesions. These outcomes are highly promising, as compared to non-HCT treatments, ${ }^{4}$ and consistent with other contemporary investigations of autologous HCT for similarly afflicted individuals. ${ }^{16-21}$

Highly active RRMS is the target population for contemporary investigations of HDIT/HCT for MS. Uniquely, among participants involved in earlier exploratory studies, those with RRMS demonstrated favorable responses, including some who experienced improved 
Table 1 Adverse events (AEs) by time of occurrence ${ }^{a}$

\begin{tabular}{|c|c|c|c|c|}
\hline \multirow[b]{3}{*}{ Time of AE occurrence ${ }^{b}$} & \multicolumn{4}{|c|}{ Enrolled participants $(n=25)$} \\
\hline & \multicolumn{2}{|l|}{ Grade $3^{c}$} & \multicolumn{2}{|l|}{ Grade $4^{\mathrm{c}}$} \\
\hline & Participants, \% ${ }^{\mathrm{d}, \mathrm{e}}$ & Events, $\mathrm{n}$ & Participants, $\%^{\mathrm{d}, \mathrm{e}}$ & Events, $\mathrm{n}$ \\
\hline All AEs & $23(92.0)$ & 138 & $25(100)$ & 94 \\
\hline Prior to start of mobilization & $1(4.0)$ & 1 & 0 & 0 \\
\hline Mobilization until start of conditioning ${ }^{f}$ & $10(40.0)$ & 20 & 5 (20.0) & 5 \\
\hline Start of conditioning to day 29 & $20(80.0)$ & 53 & $24(96.0)$ & 82 \\
\hline Days 30-99 & $8(32.0)$ & 13 & $1(4.0)$ & 1 \\
\hline Days 100-364 & $6(24.0)$ & 12 & $2(8.0)$ & 4 \\
\hline Year 1 to $<$ year 2 & 4 (16.0) & 15 & $1(4.0)$ & 1 \\
\hline Year 2 to $<$ year 3 & $6(24.0)$ & 9 & $1(4.0)$ & 1 \\
\hline Year 3 to $<$ year 4 & $7(28.0)$ & 11 & 0 & 0 \\
\hline$\geq$ Year 4 & $3(12.0)$ & 4 & 0 & 0 \\
\hline
\end{tabular}

${ }^{\text {a }} \mathrm{AEs}$ from prior to start of mobilization through completion of year 3 post- hematopoietic cell transplantation (HCT) are reported in greater detail in the interim report for this study (Nash et al., ${ }^{1}$ table 2).

${ }^{b}$ Three deaths occurred (grade 5 AEs) at 2.6, 3.9, and 4.5 years after HCT. All participants had previously experienced worsening of multiple sclerosis and met primary endpoint. No death was attributed to transplant.

${ }^{\mathrm{c}}$ Thirty-eight (28\%) of the grade $3 \mathrm{AEs}$ and 85 (90\%) of the grade $4 \mathrm{AEs}$ were hematopoietic or gastrointestinal.

${ }^{\mathrm{d}}$ Participants who experienced one or more adverse events are counted only once.

${ }^{\text {e}}$ Percentages for the number of participants with AEs are based on the number of participants in the safety population. ${ }^{f}$ One participant who was mobilized, but not subsequently transplanted, is included. This participant experienced $3 \mathrm{AEs}$, which all began between 10 and 12 days after the start of mobilization. These events are included in the "mobilization until start of conditioning" time category. The events include a grade 3 arteriovenous malformation, a grade 3 lymphopenia, and a grade 4 pulmonary embolism.

EDSS, while those with advanced primary progressive MS or secondary progressive MS (SPMS) continued to experience disability progression, possibly due to an irreversible neurodegenerative process with progression resulting from earlier immunologic injury. ${ }^{12,22-25}$

Outcomes of HDIT with autologous HCT are similar across contemporary clinical trials including HALTMS with regard to inducing sustained remissions and stability of neurologic function in participants with RRMS. ${ }^{4}$ For other contemporary investigations in which disease activity-free survival was determined, with events consisting of death or disease activity from any one of EDSS progression, relapse activity, or new MRI lesions, $68 \%$ of participants at 5 years in the Swedish experience, ${ }^{16} 68 \%$ of participants at 4 years at Northwestern University, ${ }^{17}$ and $69.6 \%$ of participants at 3 years in the Canadian study ${ }^{18}$ remained event-free. Further, in the Canadian study, none of 24 participants experienced relapses or new MRI activity and only 7 of 24 participants (29\%) experienced further disability progression at a median follow-up of 6.7 years. ${ }^{18}$ For 25 participants with RRMS reported from Italy, relapse-free survival was $70 \%$ and progression-free survival was $71 \%$ at 5 years. ${ }^{19}$

As detailed in our interim report, AEs observed in the HALT-MS study were consistent with those routinely observed after HDIT/HCT. ${ }^{1}$ AEs recorded at 4 and 5 years were not related to the transplant and, in general, were not considered severe. A third death occurred at 4.5 years posttransplant due to cardiorespiratory arrest; the 2 deaths reported previously ${ }^{1}$ were also late posttransplant at $>2.5$ and $>3.5$ years. These participants had all experienced worsening of MS, and no death was related to the study treatment.

In other contemporary studies of HDIT/HCT for RRMS, mortality has been $0 \%-4 \% \cdot{ }^{16-19,21,26}$ Regarding treatment-related mortality, 1 death among 24 participants in the Canadian study ${ }^{18}$ and 2 deaths among 74 participants in the Italian experience were attributed to transplant-related complications (a third death in that series also occurred within 3 months of transplant but was attributed to other causes). ${ }^{19}$ One death occurred among 151 participants at Northwestern University, at 30 months posttransplant, from hypertensive cardiovascular disease. ${ }^{17}$ Overall survival in these studies has otherwise been $100 \%$ for the Autologous Stem Cell Transplantation International MS Trial (ASTIMS) randomized study (9 participants received transplant ${ }^{21}$ and for the Swedish prospective observational study of 48 participants. ${ }^{16}$ These data are consistent with the recent EBMT registry report of 100-day, treatment-related mortality of $2 \%$ (for 345 MS cases), which was observed to be lower in experienced centers. ${ }^{26}$ In comparison, in a nontransplant group of patients with MS with EDSS of 3.5-5.5, MS-related mortality was $19 \%$ at 20 years of follow-up. ${ }^{27}$ 


\section{A. Event-free survival}

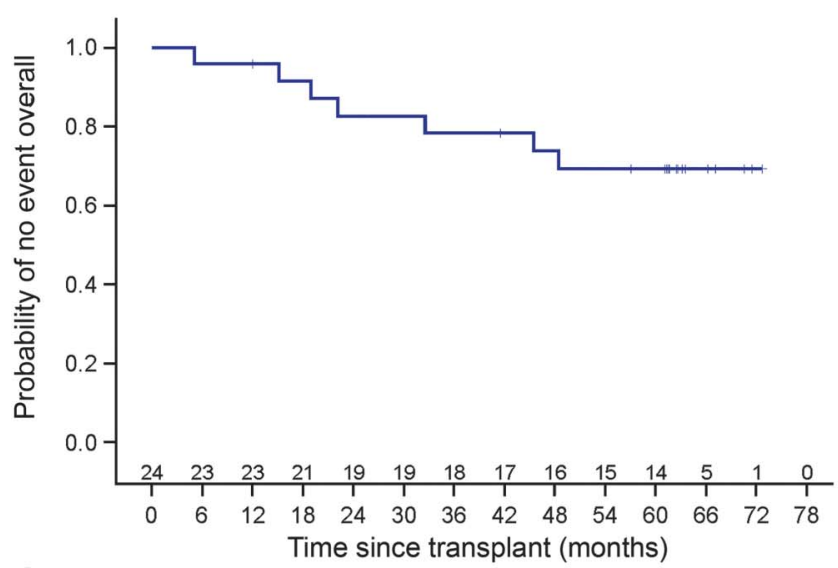

C. No EDSS progression

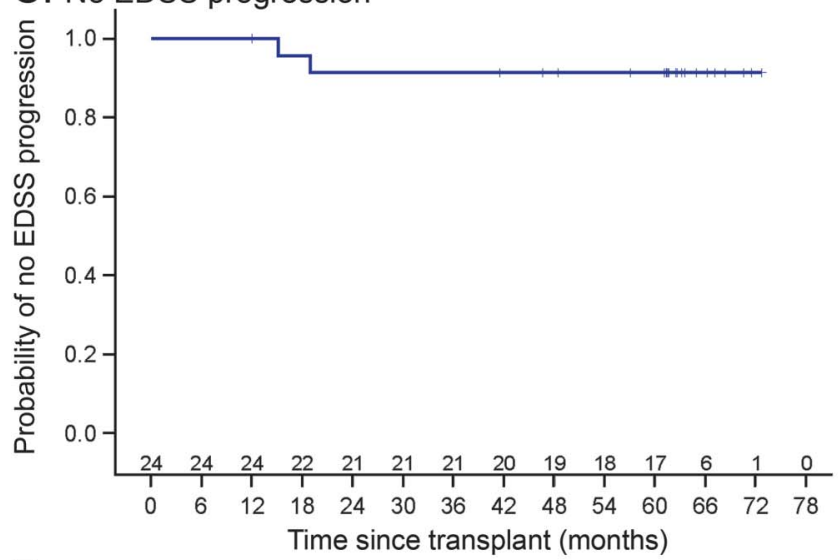

E. No MRI event

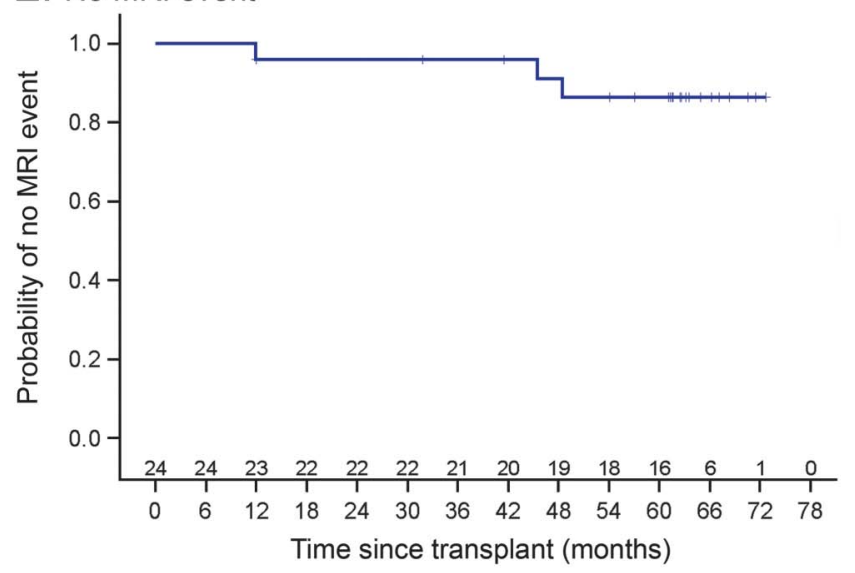

B. Summary of all primary endpoint and subsequent events

\begin{tabular}{|lcc|}
\hline & Endpoint met & $\begin{array}{c}\text { Endpoint time since } \\
\text { transplant (months) }\end{array}$ \\
\hline 1 & MRI* $^{*}$ & 45.6 \\
\hline 3 & EDSS increase* $^{*}$ & 18.9 \\
\cline { 2 - 3 } & Death $^{*}$ & 31.8 \\
\hline 4 & MRI* $^{*}$ & 48.4 \\
\hline 8 & Relapse $^{*}$ & 22.2 \\
\hline 12 & Relapse $^{*}$ & 5.1 \\
\cline { 2 - 3 } & MRI & 11.9 \\
\cline { 2 - 3 } & Death $^{*}$ & 46.5 \\
\hline 16 & EDSS $^{*}$ & 15.2 \\
\cline { 2 - 3 } & Death & 54.1 \\
\hline 19 & Relapse $^{*}$ & 32.6 \\
\hline
\end{tabular}

D. No relapse event

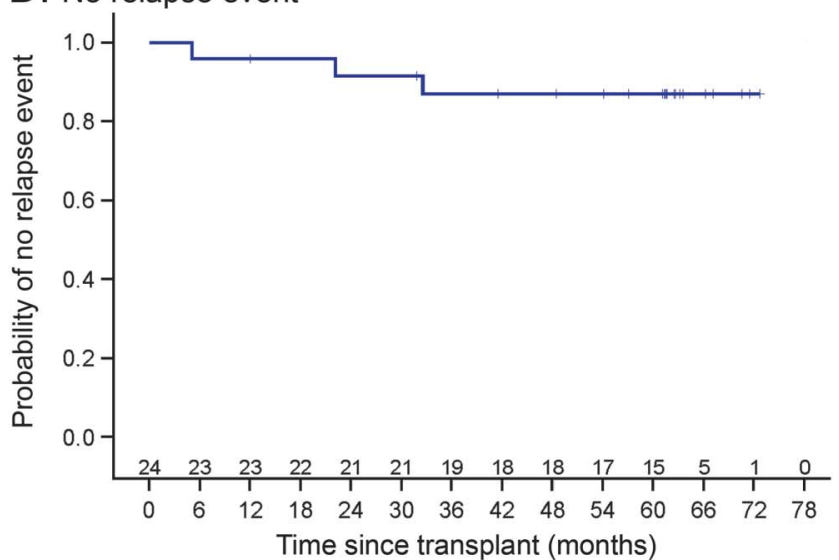

F. Overall survival

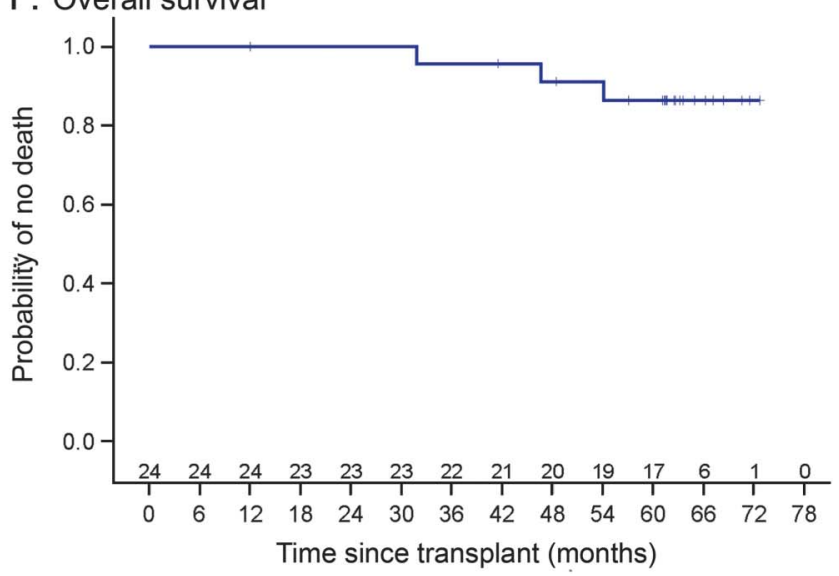

Kaplan-Meier plots of the probability an event will not occur were calculated. The number of participants at risk is presented at each time point along the $x$ axis. Short vertical bars on the curves indicate censored data. Participants who withdrew early were censored at the date of last follow-up. (A) Event-free survival (without death or disease activity from any one of: loss of neurologic function, relapse, or new lesions on MRI). (B) Summary of all primary endpoint and subsequent events by participant with type and time of event since transplant. Primary endpoint events are bolded and starred. (C) Progression-free survival (increased Expanded Disability Status Scale [EDSS] greater than 0.5 from baseline). (D) Relapse-free survival. (E) MRI activity-free survival (presence of 2 or more independent multiple sclerosis lesions indicated on MRI). Note that the MRI event that occurred at 11.9 months was not a primary endpoint event, but rather an event that occurred subsequently after the participant met primary endpoint via clinical relapse at 5.1 months. (F) Overall survival. For each of the 3 deaths, the participant had previously met primary endpoint. In the analysis of the individual components comprising event-free survival (C-F), follow-up for any component was not censored by earlier events (see text).

In another report of non-transplant patients with MS with an EDSS of 3.0-5.5, mortality was $22 \%$ at 15 years. ${ }^{28}$ Although there were no treatment-related deaths in the HALT-MS study, there is a significant risk associated with transplant and patients require counseling regarding this. 


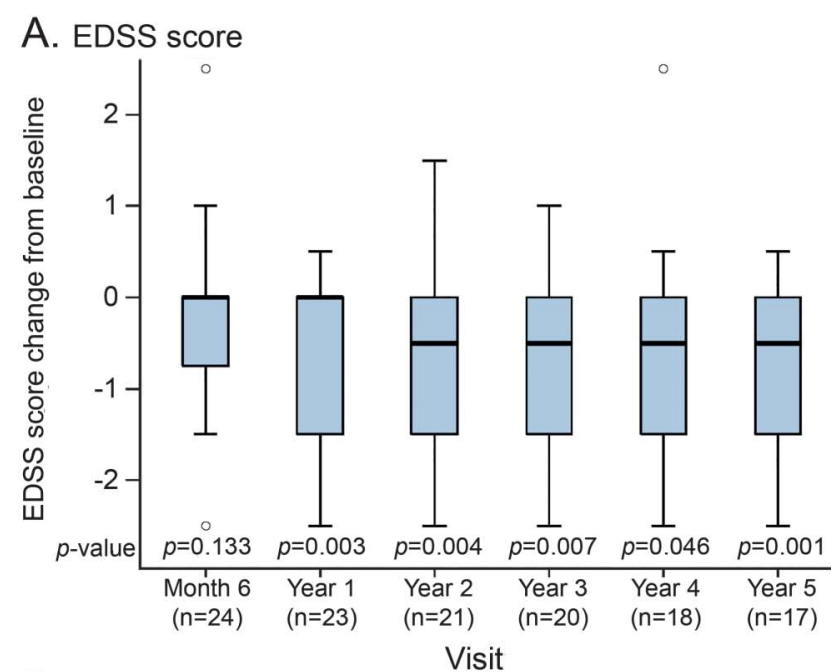

C. MSFC: PASAT-3

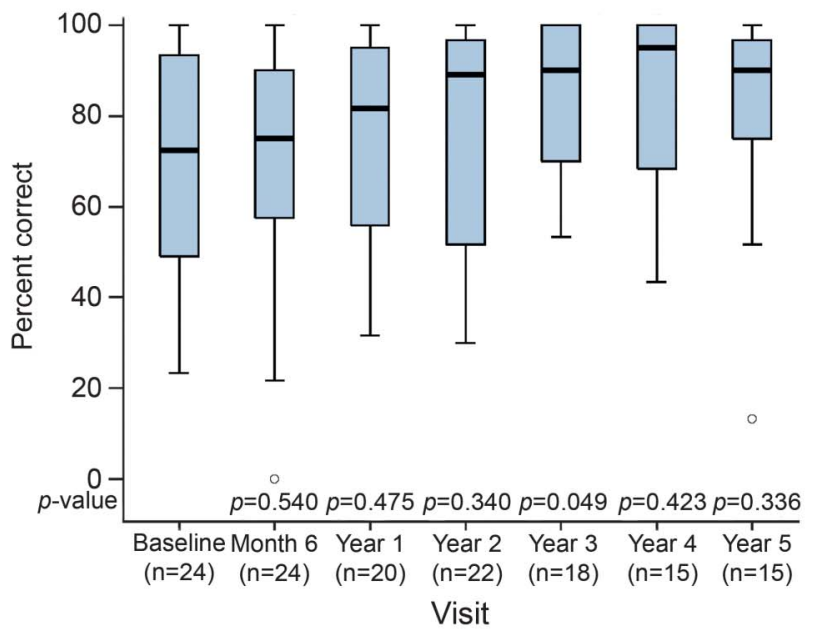

E. MSFC: Timed 25-foot walk

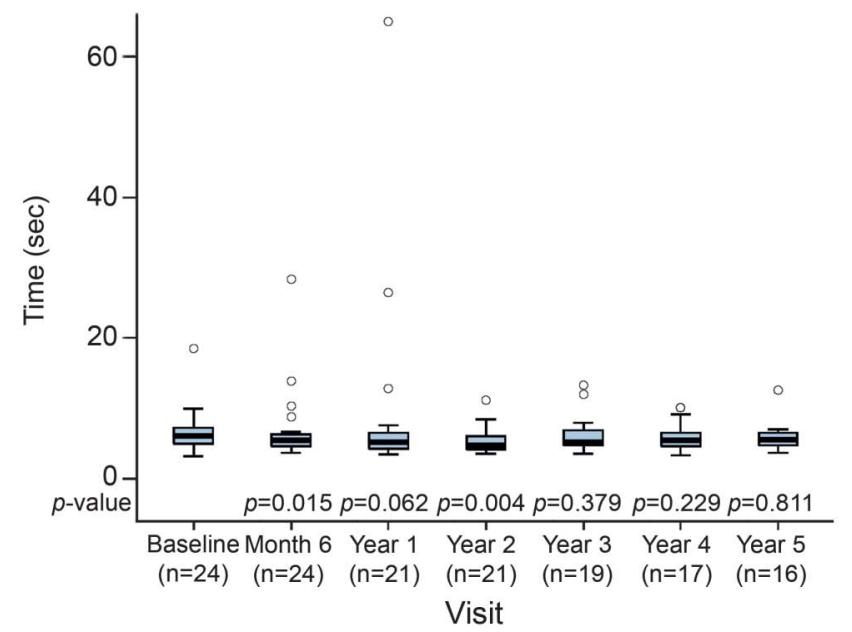

B. MSFC score

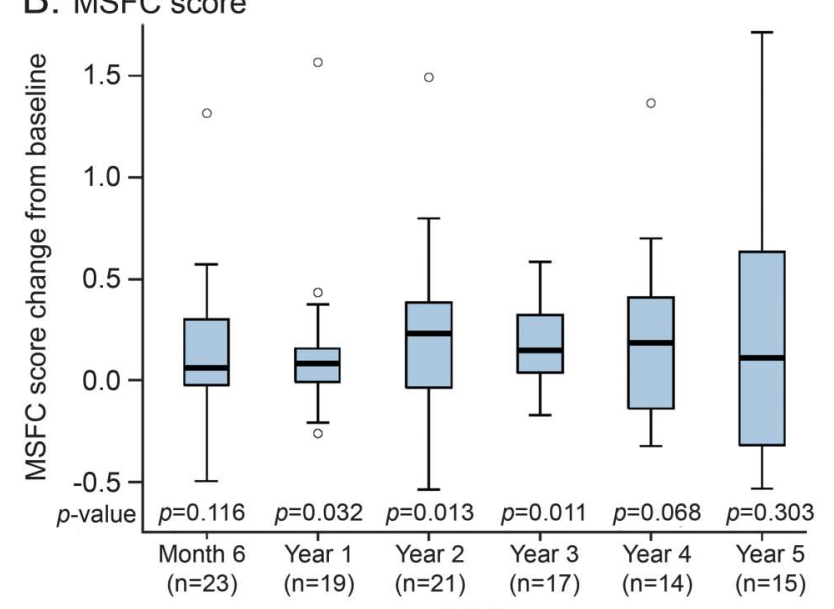

D. MSFC 9-hole peg test

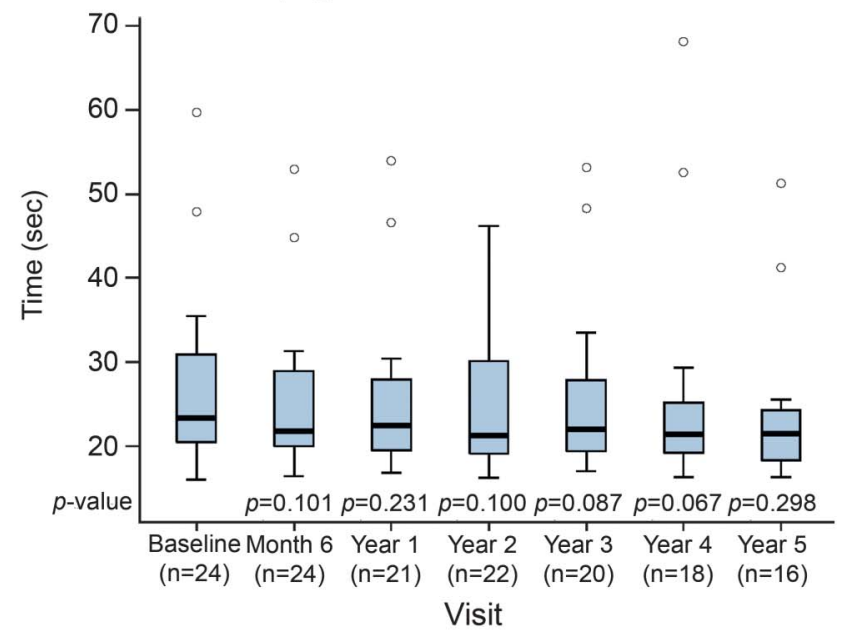

F. MSIS-29 score

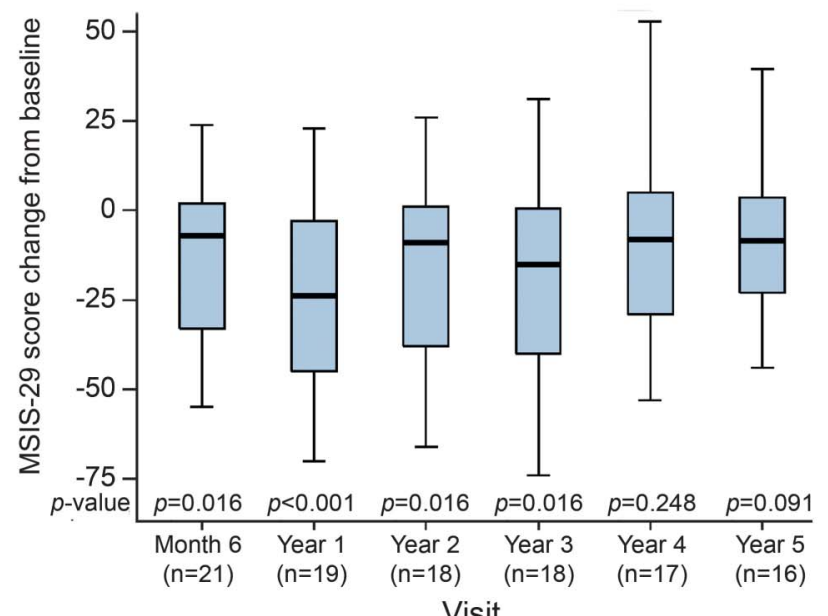

(A) Expanded Disability Status Scale (EDSS). (B) Multiple Sclerosis Functional Composite (MSFC). (C) MSFC component: 3-second Paced Auditory Serial Addition test (PASAT-3). (D) MSFC component: 9-Hole Peg Test. Average of trials from the dominant and nondominant hands. (E) MSFC component: Timed 25-Foot Walk Test. (F) Quality of life: 29-Item Multiple Sclerosis Impact Scale (MSIS-29). The $p$ values from a Wilcoxon signed-rank test are presented at each postbaseline visit along the $x$-axis assessing the change from baseline. The $p$ value in the MSFC components in panels $C$ through $E$ assesses a change in the component $Z$ score from baseline. The median component $Z$ scores can be found in table e-3. 
A. Gadolinolium-enhancing lesions

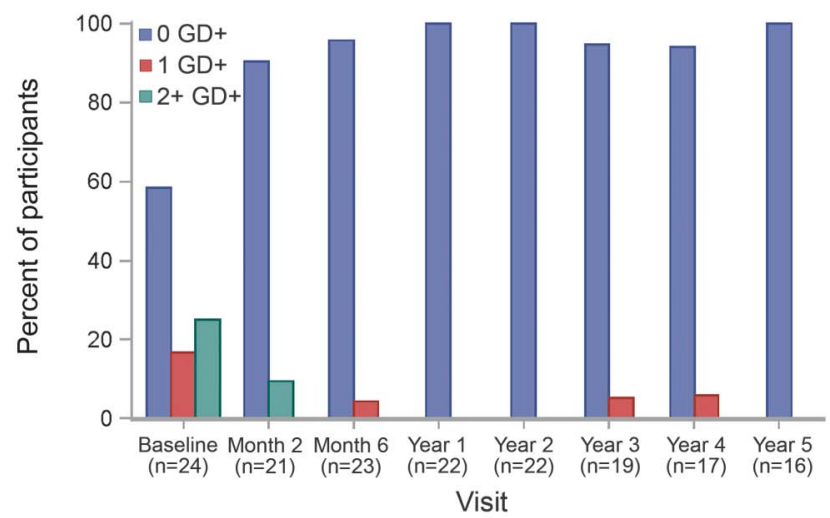

C. Change in T2 lesion volume from baseline

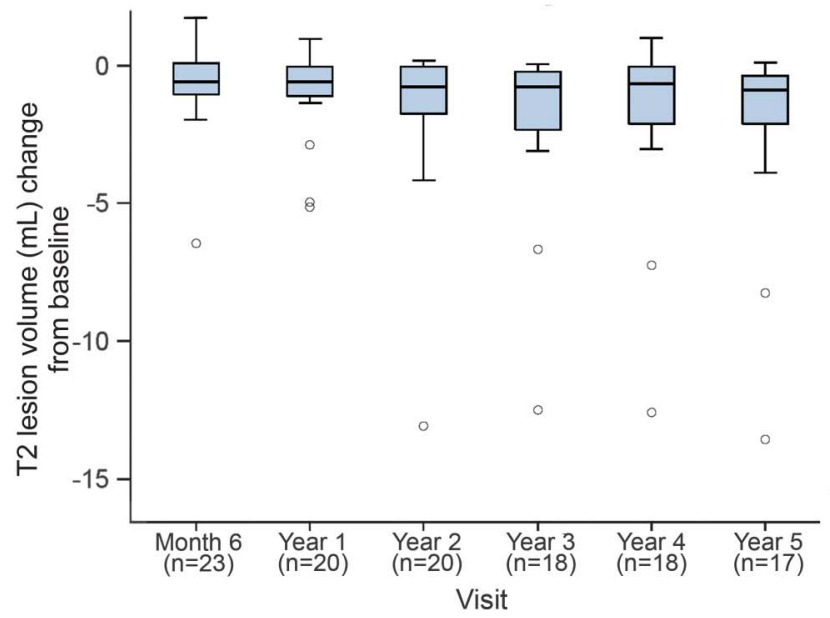

E. Change in brain volume from screening

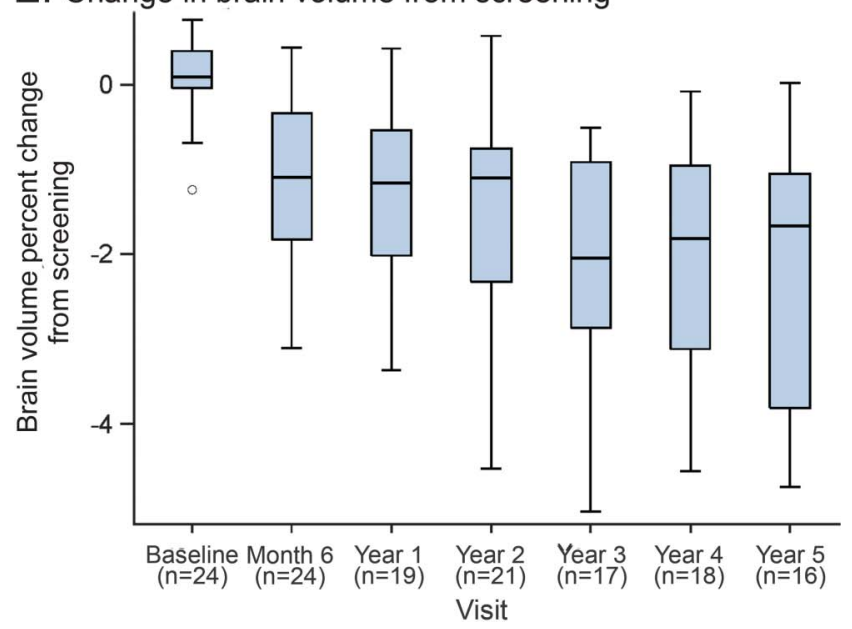

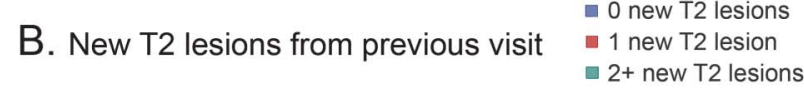

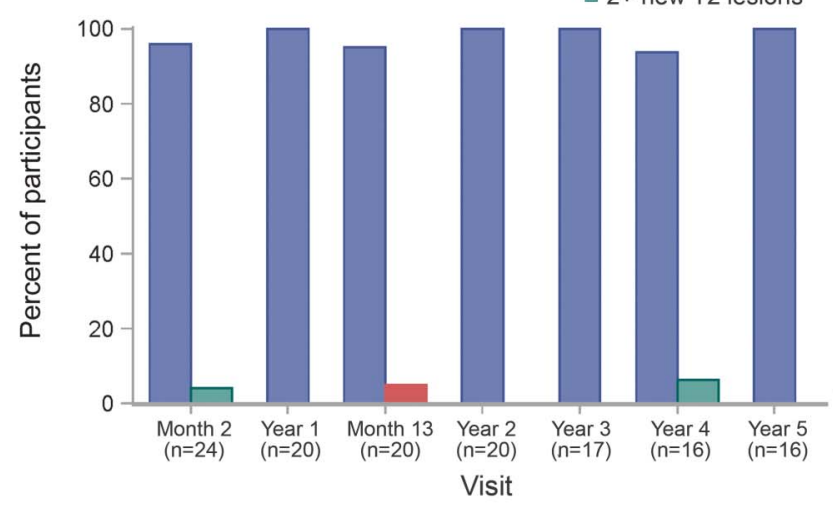

D. Change in T1 lesion volume from baseline

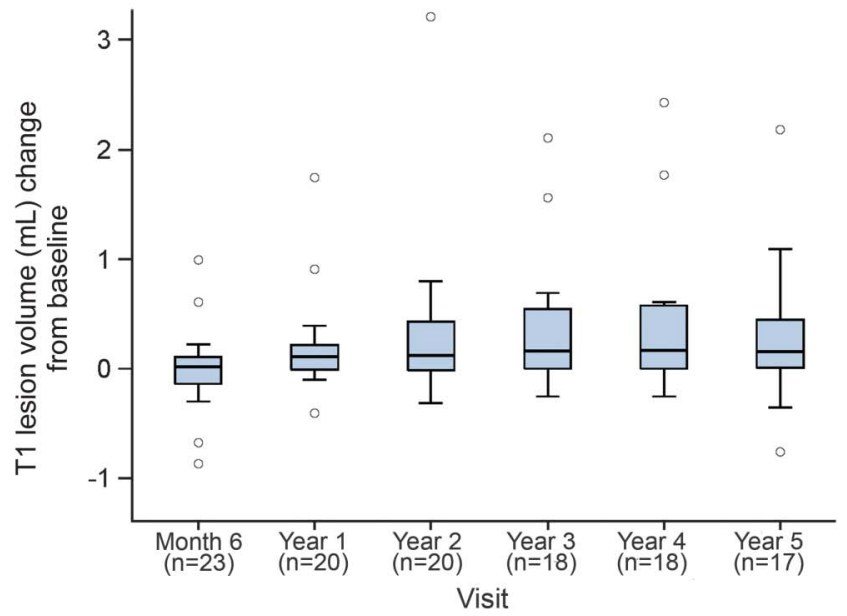

(A) New gadolinium-enhancing (GD+) lesions occurring after transplant. The GD + lesions as seen at years 3 and 4 are 2 different GD+ lesions observed in the same participant, and thus this individual met primary endpoint. (B) New T2 lesions since previous visit. The new T2 lesions seen at year 4 are in one individual, who met primary endpoint. (C) T2 lesion volume (mL) change from baseline. There was a decrease in T2 lesion volume at year 5 ( $p<0.001)$. (D) T1 lesion volume (mL) change from baseline. There was an increase in T1 lesion volume at year $5(p=0.015)$. (E) Percentage of change in brain volume from screening. At year 5 , brain volume was significantly decreased compared to baseline $(p<0.001)$; however, there was stabilization in brain volume from year 3 to $5(p=0.311)$ after transplant.

The primary goal of HDIT/HCT in the HALTMS clinical trial was to suppress active disease and prevent further disability. In addition, we note that participants who survived and completed the study experienced a median improvement in EDSS by a score of 0.5 . In the contemporary Italian experience, 
8 of 25 (31\%) participants with RRMS experienced improvement of $>1$ EDSS point at 6-12 months after HDIT/HCT, compared with 1 of 36 with SPMS. ${ }^{19}$ At Northwestern University, it was noted that 17 of $21(81 \%)$ participants with RRMS had an EDSS improvement of at least 1 point at a mean of 37 months post-HCT. ${ }^{20}$ In a larger study that included RRMS and SPMS from the same group, the baseline EDSS was 4.0, which improved to 2.5 at 4 years after $\mathrm{HDIT} / \mathrm{HCT} .{ }^{17}$ Therefore, patients with RRMS and relatively low EDSS scores may have more potential for recovery of neurologic function as compared to those with greater disability.

A markedly reduced risk of recurrent or new lesions on MRI has been observed for contemporary studies of HDIT/HCT for RRMS. This is important because appearance of new MRI lesions has been demonstrated to be correlated with relapse activity ${ }^{29}$ and with progression. ${ }^{30}$ For HALT-MS, a decrease in T2 lesion volume was observed through 5 years, and only 2 participants failed to maintain EFS by developing new lesions late after transplant. In the ASTIMS randomized study, HDIT/HCT significantly reduced MRI activity as compared to treatment with mitoxantrone. ${ }^{21}$ In the Italian experience, only 2 of 24 participants with MRI assessments at 1-2 years post-HCT had new gadolinium-enhancing lesions. ${ }^{19}$ At Northwestern University, there was a significant reduction in new gadolinium-enhancing lesions and T2 lesion volume after transplant. ${ }^{17}$ Of note, participants with active inflammation on MRI at baseline had a lower risk of progression after HDIT/HCT, as compared to those without inflammation. ${ }^{16,19,31}$

In the HALT-MS study, participants had stabilization of brain volume at 3 years through study conclusion at 5 years, consistent with attenuation of brain tissue loss following resolution of brain inflammation. A significant decrease in brain volume early after HDIT/HCT was noted in earlier studies, raising concern for brain atrophy, possibly due to high-dose chemotherapy. ${ }^{32,33}$ However, in 3 other contemporary studies, at time points beyond 2 years the rate of brain volume loss was observed to decrease, approaching normal for age. ${ }^{18,34,35}$

The MSIS was used in the HALT-MS study to measure function and QoL, and showed improvement during the first 3 years after transplant, with a trend towards improvement that did not maintain significance at 5 years. At Northwestern University, using the Short Form-36, a similar analysis demonstrated improvement at 4 years but not at 5 years, ${ }^{17}$ with the smaller number of participants available at 5 years possibly resulting in a loss of significance.

Investigation of the immunologic status of participants in the HALT-MS study with sustained remission at 5 years post-HCT vs those with disease activity may contribute to understanding mechanisms of disease in MS. We have shown that dominant CD4 + T-cell clones present pre-HCT were undetectable at 1 year post-HCT, whereas dominant $\mathrm{CD} 8+$ clones were not removed. ${ }^{3}$ Furthermore, participants who failed to respond to treatment had less diversity in their T-cell repertoire. ${ }^{3}$ Additional studies are currently underway.

Accumulating evidence supports preemptive treatment to prevent MS disease activity, to achieve best long-term outcomes. ${ }^{9,36,37}$ For patients failing firstline treatments, significantly more potent options are becoming available. ${ }^{6,37}$ We suggest that HDIT/HCT may be a reasonable consideration for such patients. Prospective clinical trials comparing HDIT/HCT to other approaches are needed. ${ }^{8}$ HDIT/HCT may represent a potential therapeutic option for patients with RRMS who fail conventional immunotherapy.

\section{AUTHOR CONTRIBUTIONS}

Richard A. Nash: study concept or design, drafting of manuscript, study supervision or coordination, acquisition of data, analysis or interpretation of the data, critical revision of the manuscript for important intellectual content. George J. Hutton: acquisition of data, analysis or interpretation of the data, critical revision of the manuscript for important intellectual content. Michael K. Racke: acquisition of data, analysis or interpretation of the data, critical revision of the manuscript for important intellectual content. Uday Popat: acquisition of data, analysis or interpretation of the data, critical revision of the manuscript for important intellectual content. Steven M. Devine: acquisition of data, analysis or interpretation of the data, critical revision of the manuscript for important intellectual content. Kaitlyn C. Steinmiller (Rho, Inc.): statistical analysis, drafting of manuscript, analysis or interpretation of the data, critical revision of the manuscript for important intellectual content. Linda M. Griffith: study concept or design, drafting of manuscript, study supervision or coordination, analysis or interpretation of the data, critical revision of the manuscript for important intellectual content. Paolo A. Muraro: study concept or design, analysis or interpretation of the data, critical revision of the manuscript for important intellectual content. Harry Openshaw: study concept or design, analysis or interpretation of the data, critical revision of the manuscript for important intellectual content. Peter H. Sayre (ITN): study concept or design, study supervision or coordination, analysis or interpretation of the data, critical revision of the manuscript for important intellectual content. Olaf Stuve: analysis or interpretation of the data, critical revision of the manuscript for important intellectual content. Douglas L. Arnold (NeuroRx): study concept or design, study supervision or coordination, acquisition of data, analysis or interpretation of the data, critical revision of the manuscript for important intellectual content. Mark H. Wener: acquisition of data, analysis or interpretation of the data, critical revision of the manuscript for important intellectual content. George E. Georges: acquisition of data, analysis or interpretation of the data, critical revision of the manuscript for important intellectual content. Annette Wundes: acquisition of data, analysis or interpretation of the data, critical revision of the manuscript for important intellectual content. George H. Kraft: study concept or design, acquisition of data, analysis or interpretation of the data, critical revision of the manuscript for important intellectual content. James D. Bowen: study concept or design, acquisition of data, analysis or interpretation of the data, critical revision of the manuscript for important intellectual content. Dr. Richard A. Nash and Kaitlyn Steinmiller had full access to all study data and take responsibility for integrity of the data and accuracy of the data analysis.

\section{ACKNOWLEDGMENT}

The authors thank the participants and their families for their involvement in this study; the research nurses, clinical coordinators, and data 
technicians for their contributions to patient care and conduct of the protocol; and the Data and Safety Monitoring Board of this study.

\section{STUDY FUNDING}

This work was sponsored by the Division of Allergy, Immunology, and Transplantation, National Institute of Allergy and Infectious Diseases (DAIT-NIAID), NIH, and conducted by the Immune Tolerance Network (ITN) (UM1 AI 109565) and DAIT-NIAID-funded statistical and clinical coordinating centers (UM2 AI 117870). The funding organization and sponsor, DAIT, NIAID, NIH, participated in design and conduct of the study; collection, management, analysis, and interpretation of the data; preparation, review, and approval of the manuscript; and the decision to submit the manuscript for publication. Baxter Healthcare Corporation, Deerfield, IL, supplied the Isolex 300i Magnetic Cell Selection System machines, Disposable Sets, and CD34 Reagent Kits used for the HALT-MS clinical trial to DAIT, NIAID, without charge. The opinions expressed are those of the authors and do not represent the position of the National Institute of Allergy and Infectious Diseases, the $\mathrm{NIH}$, or the US Government.

\section{DISCLOSURE}

R. Nash reports no disclosures relevant to the manuscript. G. Hutton receives research support from Biogen Idec, Novartis, MedImmune, Genzyme, Hoffman-LaRoche, and Opexa Therapeutics, and personal fees from Genentech and Sanofi. M. Racke receives funding from the National Institutes of Health and funding for clinical trials from Actelion, Genentech/Roche, and Novartis. He is on the editorial boards of the Annals of Neurology, the Annals of Clinical and Translational Neurology, JAMA Neurology, Therapeutic Advances in Neurologic Disorders, and the Journal of Neuroimmunology (Editor-in-Chief). He has received consultant fees from Abbvie, EMD Serono, Genentech/Roche, Novartis, Teva Neuroscience, and TG Therapeutics. U. Popat reports no disclosures relevan to the manuscript. S. Devine has received grants from NHLBI and NCI K. Steinmiller and L. Griffith report no disclosures relevant to the manuscript. P. Muraro has received travel support and speaker honoraria from Novartis, Bayer HealthCare, Bayer Pharma, Biogen Idec, Merck-Serono, and Sanofi Aventis; and received research support from the Medical Research Council UK, UK Multiple Sclerosis Society, UK Stem Cell Foundation, and Italian Multiple Sclerosis Foundation (FISM) H. Openshaw and P. Sayre report no disclosures relevant to the manuscript. O. Stuve serves on the editorial boards of JAMA Neurology, Multiple Sclerosis Journal, and Therapeutic Advances in Neurologic Disorders; receives grant support from Teva Pharmaceuticals and Opexa Therapeutics; and is funded by a Merit Review grant (federal award document number [FAIN] I01BX001674) from the US Department of Veterans Affairs, Biomedical Laboratory Research and Development. Dr. Stuve has served on data monitoring committees for Pfizer and Sanofi-Aventis without monetary compensation. Dr. Stuve collaborated with Medscape on educational initiatives, represented Novartis in front of a Scientific Advisory Group at the European Medicines Agency (EMA) and has advised Genentech and Sanofi-Aventis. Dr. Stuve has participated in a Teva-sponsored meeting, consulted for Navigant Consulting, and received travel support from Pfizer. D. Arnold receives payments to NeuroRx Research from NIH/NIAID and ITN and personal fees for consulting from Acorda, Biogen, Hoffman LaRoche, MedImmune, Mit subishi, Novartis, Receptos, and Sanofi-Aventis; grants from Biogen and Novartis; and an equity interest in NeuroRx Research, which was the image analysis center for this trial. M. Wener receives grant support from BioRad, consultation fees from Cellgene \& MedImmune, and royaltie from UpToDate and Medical Training Software. G. Georges reports no disclosures relevant to the manuscript. A. Wundes received grants from Biogen Idec and personal fees from Biogen Idec and Acorda Therapeutics. G. Kraft is a member of the Acorda Therapeutics AXoN Advisory Council. J. Bowen receives grant support from N01AI15416, NIH/ NIAID; personal fees and research contracts from Acorda Therapeutics, Biogen IDEC, EMD Serono, Novartis, and Genzyme; research contracts from Alexion, Avanir, Genentech, GlaxoSmithKline, Sanofi-Aventis, Osmotica, Roche, Xenoport, Opexa, and Allergan; consults for Teva Neuroscience; and is a stockholder in Amgen. Go to Neurology.org for full disclosures.

\section{REFERENCES}

1. Nash RA, Hutton GJ, Racke MK, et al. High-dose immunosuppressive therapy and autologous hematopoietic cell transplantation for relapsing-remitting multiple sclerosis (HALT-MS): a 3-year interim report. JAMA Neurol 2015;72:159-169.

2. Muraro PA, Douek DC, Packer A, et al. Thymic output generates a new and diverse TCR repertoire after autologous stem cell transplantation in multiple sclerosis patients. J Exp Med 2005;201:805-816.

3. Muraro PA, Robins $\mathrm{H}$, Malhotra S, et al. T cell repertoire following autologous stem cell transplantation for multiple sclerosis. J Clin Invest 2014;124:1168-1172.

4. Sormani MP, Muraro PA, Saccardi R, Mancardi G. NEDA status in highly active MS can be more easily obtained with autologous hematopoietic stem cell transplantation than other drugs. Mult Scler Epub 2016 Apr 26.

5. Imitola J, Racke MK. Is no evidence of disease activity a realistic goal for patients with multiple sclerosis? JAMA Neurol 2015;72:145-147.

6. Torkildsen O, Myhr K-M, Bo L. Disease-modifying treatments for multiple sclerosis: a review of approved medications. Eur J Neurol 2015;23(suppl 1):18-27.

7. Havrdova E, Galetta S, Hutchinson M, et al. Effect of natalizumab on clinical and radiological disease activity in multiple sclerosis: a retrospective analysis of the natalizumab safety and efficacy in relapsing-remitting multiple sclerosis (AFFIRM) study. Lancet Neurol 2009;8:254-260.

8. Cohen JA, Coles AJ, Arnold DL, et al. Alemtuzumab versus interferon beta $1 \mathrm{a}$ as first-line treatment for patients with relapsing-remitting multiple sclerosis: a randomized controlled phase 3 trial. Lancet 2012;380:1819-1828.

9. Rotstein DL, Healy BC, Malik MT, Chitnis T, Weiner HL. Evaluation of no evidence of disease activity in a 7-year longitudinal multiple sclerosis cohort. JAMA Neurol 2015;72:152-158.

10. McDonald WI, Compston A, Edan G, et al. Recommended diagnostic criteria for multiple sclerosis: guidelines from the International Panel on the diagnosis of multiple sclerosis. Ann Neurol 2001;50:121-127.

11. Kurtzke JF. Rating neurologic impairment in multiple sclerosis: an expanded disability status scale (EDSS). Neurology 1983;33:1444-1452.

12. Fassas A, Anagnostopoulos A, Kazis A, et al. Peripheral blood stem cell transplantation in the treatment of progressive multiple sclerosis: first results of a pilot study. Bone Marrow Transpl 1997;20:631-638.

13. Nash RA, Bowen JD, McSweeney PA, et al. High-dose immunosuppressive therapy and autologous peripheral blood stem cell transplantation for severe multiple sclerosis. Blood 2003;102:2364-2372.

14. Freedman MS, Thompson EJ, Deisenhammer F, et al. Recommended standard of cerebrospinal fluid analysis in the diagnosis of multiple sclerosis: a consensus statement. Arch Neurol 2005;62:865-870.

15. Cutter GR, Baier ML, Rudick RA, et al. Development of a multiple sclerosis functional composite as a clinical trial outcome measure. Brain 1999;122:871-882.

16. Burman J, Iacobaeus E, Svenningsson A, et al. Autologous haematopoietic stem cell transplantation for aggressive multiple sclerosis: the Swedish experience. J Neurol Neurosurg Psychiatry 2014;85:1116-1121. 
17. Burt RK, Balabanov R, Han X, et al. Association of nonmyeloablative hematopoietic stem cell transplantation with neurological disability in patients with relapsing-remitting multiple sclerosis. JAMA 2015;313:275-284.

18. Atkins HL, Bowman M, Allan D, et al. Immunoablation and autologous haemopoietic stem-cell transplantation for aggressive multiple sclerosis: a multicentre single-group phase 2 trial. Lancet 2016;388:576-585.

19. Mancardi GL, Sormani MP, Di Gioia M, et al. Autologous haematopoietic stem cell transplantation with an intermediate intensity conditioning regimen in multiple sclerosis: the Italian multi-centre experience. Mult Scler 2012;18:835-842.

20. Burt RK, Loh Y, Cohen B, et al. Autologous nonmyeloablative haemopoietic stem cell transplantation in relapsing-remitting multiple sclerosis: a phase I/II study. Lancet Neurol 2009;8:244-253.

21. Mancardi GL, Sormani MP, Gualandi F, et al. Autologous hematopoietic stem cell transplantation in multiple sclerosis: a phase II trial. Neurology 2015;84:981-988.

22. Mancardi G, Saccardi R. Autologous haematopoietic stem-cell transplantation in multiple sclerosis. Lancet Neurol 2008;7: 626-636.

23. Rush CA, MacLean HJ, Freedman MS. Aggressive multiple sclerosis: proposed definition and treatment algorithm. Nat Rev Neurol 2015;11:379-389.

24. Frischer JM, Bramow S, Dal-Bianco A, et al. The relation between inflammation and neurodegeneration in multiple sclerosis brains. Brain 2009;132:1175-1189.

25. Bowen JD, Kraft GH, Wundes A, et al. Autologous hematopoietic cell transplantation following high-dose immunosuppressive therapy for advanced multiple sclerosis: long-term results. Bone Marrow Transpl 2012;47: 946-951.

26. Farge D, Labopin M, Tyndall A, et al. Autologous hematopoietic stem cell transplantation for autoimmune diseases: an observational study on 12 years' experience from the European group for blood and marrow transplantation working party on autoimmune diseases. Haematologica 2010;95:284-292.

27. Hirst C, Ingram G, Swingler R, Compston DA, Pickersgill T, Robertson NP. Change in disability in patients with multiple sclerosis: a 20-year prospective populationbased analysis. J Neurol Neurosurg Psychiatry 2008;79: 1137-1143.
28. Daumer M, Griffith LM, Meister W, Nash RA, Wolinsky JS. Survival, and time to an advanced disease state or progression, of untreated patients with moderately severe multiple sclerosis in a multicenter observational database: relevance for design of a clinical trial for high dose immunosuppressive therapy with autologous hematopoietic stem cell transplantation. Mult Scler 2006;12:174-179.

29. Sormani MP, Bruzzi P. MRI lesions as a surrogate for relapses in multiple sclerosis: a meta-analysis of randomised trials. Lancet Neurol 2013;12:669-676.

30. Sormani MP, Bonzano L, Roccatagliata L, Mancardi GL, Uccelli A, Bruzzi P. Surrogate endpoints for EDSS worsening in multiple sclerosis. A meta-analytic approach. Neurology 2010;75:302-309.

31. Fassas A, Kimiskidis VK, Sakellari I, et al. Long-term results of stem cell transplantation for MS: a single-center experience. Neurol 2011;76:1066-1070.

32. Chen JT, Collins DL, Atkins HL, Freedman MS, Galal A, Arnold DL. Brain atrophy after immunoablation and stem cell transplantation in multiple sclerosis. Neurology 2006; 66:1935-1937.

33. Jager HR, Williams EJ, Savage DG, et al. Assessment of brain changes with registered MR before and after bone marrow transplantation for chronic myeloid leukemia. AJNR Am J Neuroradiol 1996;17:1275-1282.

34. Roccatagliata L, Rocca M, Valsasina P, et al. The longterm effect of AHSCT on MRI measures of MS evolution: a five-year follow-up study. Mult Scler 2007;13: $1068-1070$.

35. Lee H, Narayanan S, Brown RA, et al. Brain atrophy after bone marrow transplantation for treatment of multiple sclerosis. Mult Scler Epub 2016 May 31.

36. Fisniku LK, Brex PA, Altmann DR, et al. Disability and T2 MRI lesions: a 20-year follow-up of patients with relapse onset of multiple sclerosis. Brain 2008;131: 808-817.

37. Stangel M, Penner IK, Kallmann BA, Lukas C, Kieseier BC. Towards the implementation of "no evidence of disease activity" in multiple sclerosis treatment: the multiple sclerosis decision model. Ther Adv Neurol Disord 2015;8:3-13.

38. Saccardi R, Freedman MS, Sormani MP, et al. A prospective, randomized, controlled trial of autologous haematopoietic stem cell transplantation for aggressive multiple sclerosis: a position paper. Mult Scler 2012;18:825-834.

\section{Subspecialty Alerts by E-mail!}

Customize your online journal experience by signing up for e-mail alerts related to your subspecialty or area of interest. Access this free service by visiting Neurology.org/site/subscriptions/etoc.xhtml or click on the "E-mail Alerts" link on the home page. An extensive list of subspecialties, methods, and study design choices will be available for you to choose from—allowing you priority alerts to cutting-edge research in your field! 


\section{Neurology}

\section{High-dose immunosuppressive therapy and autologous HCT for relapsing-remitting MS}

Richard A. Nash, George J. Hutton, Michael K. Racke, et al. Neurology 2017;88;842-852 Published Online before print February 1, 2017

DOI 10.1212/WNL.0000000000003660

\section{This information is current as of February 1, 2017}

\section{Updated Information \& Services}

Supplementary Material

\section{References}

Citations

Subspecialty Collections

Permissions \& Licensing

Reprints including high resolution figures, can be found at: http://n.neurology.org/content/88/9/842.full

Supplementary material can be found at: http://n.neurology.org/content/suppl/2017/02/01/WNL.0000000000003 660.DC1

http://n.neurology.org/content/suppl/2018/03/27/WNL.0000000000003 660.DC2

This article cites 36 articles, 9 of which you can access for free at: http://n.neurology.org/content/88/9/842.full\#ref-list-1

This article has been cited by 4 HighWire-hosted articles: http://n.neurology.org/content/88/9/842.full\#\#otherarticles

This article, along with others on similar topics, appears in the following collection(s):

Autoimmune diseases

http://n.neurology.org/cgi/collection/autoimmune_diseases Multiple sclerosis

http://n.neurology.org/cgi/collection/multiple_sclerosis

Information about reproducing this article in parts (figures,tables) or in its entirety can be found online at:

http://www.neurology.org/about/about_the_journal\#permissions

Information about ordering reprints can be found online:

http://n.neurology.org/subscribers/advertise

Neurology ${ }^{\circledR}$ is the official journal of the American Academy of Neurology. Published continuously since 1951, it is now a weekly with 48 issues per year. Copyright Copyright (C) 2017 The Author(s). Published by Wolters Kluwer Health, Inc. on behalf of the American Academy of Neurology. All rights reserved. Print ISSN: 0028-3878. Online ISSN: 1526-632X.

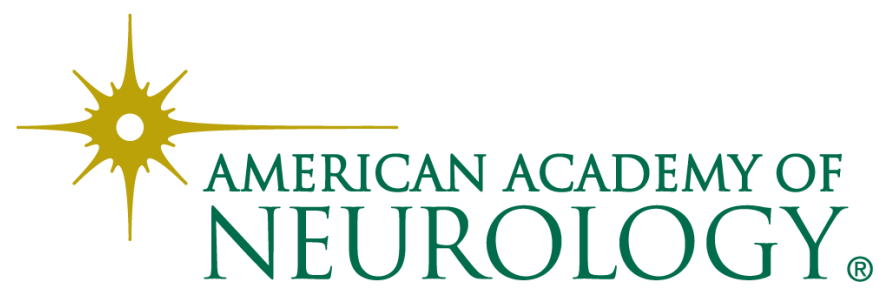

